\title{
Study on Void Structure Reconstruction of Asphalt Mixture by X-Ray Computed Tomography and Otsu's Method
}

\author{
Jiantong Zhang $\mathbb{D}^{1,2}$ Jun Yang $\mathbb{D}^{3}{ }^{3}$ Tiejun Liu, ${ }^{1}$ Rongxing Cai, ${ }^{1}$ and Rui Yang ${ }^{4}$ \\ ${ }^{1}$ Shenzhen Municipal Engineering Corporation, Shenzhen 518109, China \\ ${ }^{2}$ School of Civil and Transportation Engineering, Guangdong University of Technology, Guangzhou 510006, China \\ ${ }^{3}$ School of Transportation, Southeast University, 2\#Sipailou, Nanjing, Jiangsu 210096, China \\ ${ }^{4}$ Department of Civil and Architecture Engineering, Tianhe College of Guangdong Polytechnic Normal University, \\ Guangzhou 510540, China
}

Correspondence should be addressed to Jun Yang; yangjun@seu.edu.cn

Received 11 March 2020; Revised 24 April 2020; Accepted 13 July 2020; Published 31 August 2020

Academic Editor: Stefano Sorace

Copyright (c) 2020 Jiantong Zhang et al. This is an open access article distributed under the Creative Commons Attribution License, which permits unrestricted use, distribution, and reproduction in any medium, provided the original work is properly cited.

\begin{abstract}
The purpose of this paper is to obtain the pore distribution of asphalt mixture accurately by nondestructive technology. Specimens prepared with four gradations of asphalt mixtures were scanned using X-ray computed tomography (CT) which was used to measure air void sizes at different depths within specimens. The air void distributions of obtained CT images were analyzed using ring blocking segmentation combining Otsu's method, which provided an accurate estimate of air voids in asphalt mixtures. The image processing results showed that air void distribution was not uniform in the specimens; higher air void concentrations were found at the top and bottom of the specimen, and lower, in the rest of the sample depth. The air void sizes of SUP13 and AC13 are mainly distributed between 0.15 to $0.2 \mathrm{~mm}$, while PA13 and SMA13 are 0.4 to $0.65 \mathrm{~mm}$ and 0.4 to $0.7 \mathrm{~mm}$, respectively. It is believed that the CT pictures processed by the ring blocking segmentation combining Otsu's method is feasible and rational to capture the air voids size and content of asphalt mixtures.+
\end{abstract}

\section{Introduction}

Performances of asphalt mixtures are dependent on the volume of aggregate, asphalt binder, as well as air voids. Specifically, the stiffness of the mixture is highly related to the air void content of the mixture. It is generally accepted that air voids play an important role in determining the resistance of asphalt mixtures to major pavement distresses including rutting, fatigue cracking, and low temperature cracking [1]. The research shows that stiffness and compressive strength increase with decreasing air void content, when the binder content is kept constant [2]. Air void content also influences the durability of asphalt mixes in terms of aging and stripping. For example, low air void content minimizes the aging of the asphalt binder films within the aggregate mass, the possibility of water penetrating into the mix, and stripping the asphalt binder off the aggregates [3]. It is also found that low air void content can lead to asphalt bleeding [4], while high air voids may result in early aging processes of the mixture, which make it prone to moisture damage, cracking, and pavement deterioration [5].

Air void content is a common parameter used to characterize the void structure of compacted asphalt mixtures [6]. It should be noted that the level of homogeneity of the distribution of air voids inside the asphalt course has significant impacts on the response of the material [7-11]. It is necessary to further study the characterization of air voids such as void's size including radius and area of air void, distribution, and content. However, it is difficult to obtain the air void characterization by using traditional techniques. Therefore, the computer imaging technology and nondestructive techniques which can solve the problem described above and have the ability to characterize internal structure 
of materials [12-14] were applied in this study. First of all, CT technology is used to scan asphalt mixture specimens. The microstructure characteristics of asphalt mixture, such as voids and coarse aggregate, are studied using Otsu image processing method, MATLAB software, and image processing software, and then the virtual asphalt mixture specimen is reconstructed.

\section{Objectives}

The objective of this study is to investigate the air void distribution (i.e., air void content and air void size) using $\mathrm{X}$-ray CT, Otsu image processing method, and MATLAB software. Image analysis software and computer algorithms were used to analyze the X-ray CT images and quantify the air void content, size distribution, and connectivity.

\section{Test Materials and Sample Preparation}

Specimens with $150 \mathrm{~mm}$ in diameter and $165 \mathrm{~mm}$ in height were fabricated using the superpave gyratory compactor (SGC). In order to obtain high definition CT picture, the specimens were further cored into $50 \mathrm{~mm}$ in diameter and $75 \mathrm{~mm}$ in height for test purposes. Four types of asphalt mixtures known as AC13, SMA13, PA13, and SUP13 were studied in details. The aggregate gradations for the four mixtures are shown in Table 1.

SBS-modified asphalt was used in AC13, SUP13, and SMA13, and high-viscosity asphalt was used in PA13. The properties of SBS-modified asphalt and high-viscosity asphalt are shown in the Table 2. The optimum binder content is $5.36 \%, 5 \%, 5.9 \%$, and $4.85 \%$ for AC13, SUP13, SMA13, and PA13, respectively. The air void content is 4.7\%, 4.1\%, 4.0\%, and $18.5 \%$ for AC13, SUP13, SMA13, and PA13.

\section{X-Ray CT Scanning and Image Analysis Techniques}

4.1. Image Scanning Analysis Study. The specimens were nondestructively scanned using an X-ray CT machine to generate a map representing the density at every point in the microstructure with the resolution of approximately $0.083 \mathrm{~mm} /$ pixel. Horizontal two-dimensional image slices were captured relative to the specimen's height from bottom to top at every $0.1 \mathrm{~mm}$ interval. $750 \mathrm{CT}$ images were obtained using X-ray CT scanning for each specimen. The 8-bit grayscale images have a range of pixel intensities from 0 (pure black) to 255 (pure white). The geometry of the cylindrical specimen and an example of a captured X-ray CT image are shown in Figure 1. Two imaging software packages, MATLAB, and Image-Pro Plus, were used to process and analyze the CT images.

4.2. Otsu's Method. In image segmentation, threshold segmentation is common and effective method especially when the objective and background grayscale are distinctively different. Otsu [16] presented the maximum class square error method (that is, Otsu's method) which was simple,
TABle 1: Compositions and aggregate gradations of asphalt mixtures.

\begin{tabular}{lcccc}
\hline \multirow{2}{*}{ Sieve size $(\mathrm{mm})$} & \multicolumn{4}{c}{ \% passing by weight } \\
& AC13 & SUP13 & SMA13 & PA13 \\
\hline 16 & 100 & 100 & 100 & 100 \\
13.2 & 95.9 & 97.1 & 96.7 & 97.7 \\
9.5 & 76.8 & 78.8 & 59.1 & 70.2 \\
4.75 & 50.7 & 53.0 & 25.5 & 21.2 \\
2.36 & 34.4 & 32.5 & 22.0 & 16.4 \\
1.18 & 25.2 & 19.9 & 18.3 & 12.6 \\
0.6 & 18.3 & 15.3 & 14.9 & 9.1 \\
0.3 & 13.5 & 9.4 & 12.8 & 6.9 \\
0.15 & 10.6 & 7.2 & 11.7 & 5.8 \\
0.075 & 7.2 & 5.5 & 10.5 & 5.1 \\
\hline
\end{tabular}

Note: the number of each mix represents the nominal maximum aggregate size.

adaptive, and widely used in threshold segmentation. Otsu's method was used to characterize the microstructure of asphalt mixtures [17].

In Otsu's algorithm, supposing the image has $L$ gray levels (the gray value ranges from $[1,2 \cdots L]$ ) and considers the pixel of which gray value is $i$, so the total pixel numbers $n_{i}$ are obtained by

$$
N=\sum_{i=0}^{L-1} n_{i}
$$

Assuming the entire image is divided by gray value $t$ into regions $\mathrm{A}$ (background) and region $\mathrm{B}$ (destination), the gray level of region A ranges from 1 to $t$, the gray level of region $\mathrm{B}$ ranges from $t+1$ to $L-1$, the class probabilities of A and B are estimated as equations (2) and (3), respectively.

$$
\begin{aligned}
& p_{A}=\sum_{i=0}^{t} p_{i}, \\
& p_{B}=\sum_{i=t+1}^{L-1} p_{i}=1-p_{A} .
\end{aligned}
$$

Thus, the gray level of A and B can be calculated using the following equations:

$$
\begin{aligned}
& w_{A}=\sum_{i=0}^{t} \frac{i p_{i}}{p_{A}}, \\
& w_{B}=\sum_{i=t+1}^{L-1} \frac{i p_{i}}{p_{B}},
\end{aligned}
$$

and the total gray value of image is expressed as

$$
w_{0}=p_{A} w_{A}+p_{B} w_{B}=\sum_{i=t+1}^{L-1} p_{i} .
$$

The class variance expression between regions A and B is calculated as follows:

$$
\sigma^{2}=p_{A}\left(w_{A}-w_{0}\right)^{2}+p_{B}\left(w_{B}-w_{0}\right)^{2} .
$$


TABLE 2: Properties of SBS-modified asphalt and high-viscosity asphalt.

\begin{tabular}{lccc}
\hline Properties & & Value & Testing method [11] \\
\hline Penetration $\left(25^{\circ} \mathrm{C}, 0.1 \mathrm{~mm}\right)$ & SBS-modified asphalt & High-viscosity asphalt & T0604 \\
Ductility $\left(5^{\circ} \mathrm{C}, 5 \mathrm{~cm} / \mathrm{min}\right)$ & 54 & 46 & $\mathrm{~T} 0605$ \\
Softening point $\left({ }^{\circ} \mathrm{C}\right)$ & 39 & 120 & $\mathrm{~T} 0606$ \\
Density $\left(15^{\circ} \mathrm{C}, \mathrm{g} / \mathrm{cm} 3\right)$ & 77 & 1.04 & $\mathrm{~T} 0662$ \\
TFOT residue $\left(163^{\circ} \mathrm{C}, 5 \mathrm{~h}\right)$ & 1.03 & -1.6 & $\mathrm{~T}$ \\
Mass loss $(\%)$ & -0.3 & 182 & $\mathrm{~T} 0610$ \\
Residue penetration $\left({ }^{\circ} \mathrm{C}\right)$ & 92 & 10.6 & $\mathrm{~T} 0604$ \\
Ductility $\left(5^{\circ} \mathrm{C}, 5 \mathrm{~cm} / \mathrm{min}\right)$ & 10.3 & $\mathrm{~T} 0605$ \\
\hline
\end{tabular}

Note: the testing method is conducted according to the Standard Test Methods of Bitumen and Bituminous Mixtures for Highway Engineering (JTG E202011) [15].
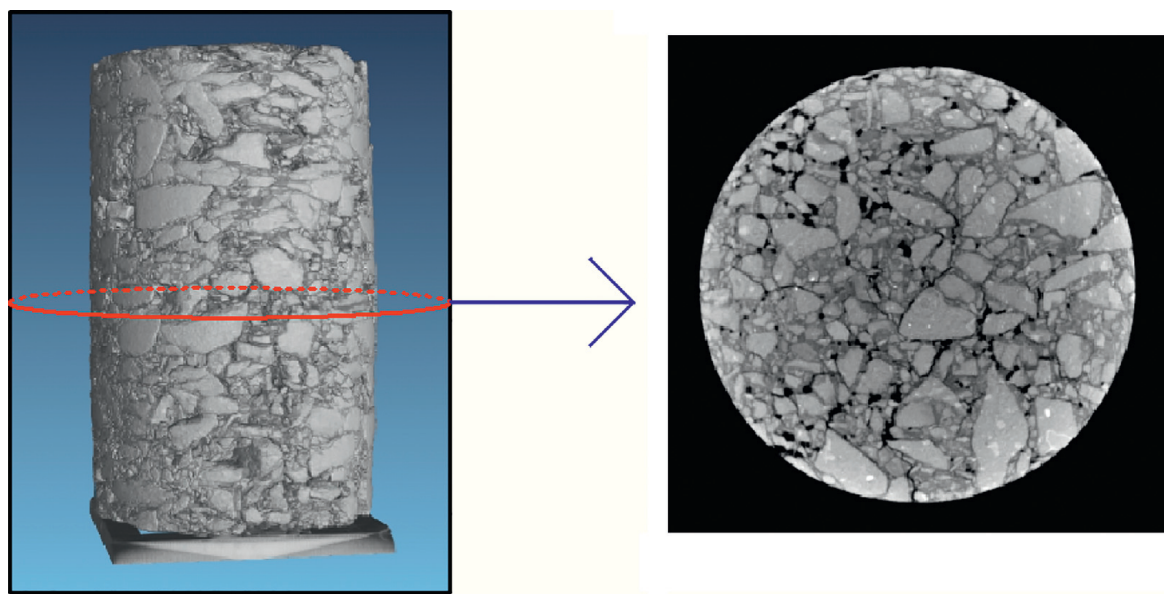

Figure 1: Images of asphalt mixtures specimen scanned using CT X-ray.

According to equation (6), the largest $t$ value is the optimum value needed for complete image segmentation. The optimized threshold $t^{*}$ is given by

$$
\sigma\left(t^{*}\right)=\operatorname{Max}_{0 \leq t \leq L-1}\{\sigma(t)\} .
$$

In a recursion algorithm, the class probabilities and class means are given in equations (8)(10), respectively.

$$
\begin{aligned}
& p_{A}(t+1)=p_{A}(t)+P_{(t+1)}, \\
& w_{A}(t+1)=\frac{p_{A}(t) w_{A}(t)+(t+1) P_{(t+1)}}{p_{A}(t+1)}, \\
& w_{B}(t+1)=\frac{w_{0}-p_{A}(t+1) w_{A}(t+1)}{1-p_{A}(t+1)} .
\end{aligned}
$$

4.3. Image Processing and Analysis Using Ring Blocking Method and Otsu's Method. Image threshold processing plays an important role in image segmentation. According to the characterization of the grayscale which is increasing from the center to the edge of CT pictures for the same phase (there are three phases in asphalt mixtures, that is, aggregate, air void, and asphalt mastic), the CT pictures are segmented using ring block (shown in Figure 2) combining Otsu's method to characterize the microstructure of asphalt mixtures [18]. The CT pictures are segmented with 5 rings as shown in Figure 2.

Image processing is explained in following steps. Firstly, the image analysis process includes the image format, noise reduction, image enhancement, and a hole filling algorithm to recognize the hole region. Secondly, the preprocessed image is segmented using the ring blocking method. And there are $50 \%$ overlaps among the adjacent rings. Thirdly, the ring segmentation regions are processed using Otsu's method to calculate the threshold of air voids and the background. Finally, the ring segmentation regions are combined to obtain the whole segmentation image (Figure 3). The aggregate, air void, and asphalt mastic of each segmentation image are captured using Otsu's method as shown in Figure 3(c).

In order to illustrate the validity and accuracy of ring blocking segmentation combining Otsu's method, Bernsen's method [19] and traditional Otsu's method are also used to process the CT pictures. Otsu's method is the global threshold technique, and Bernsen's method is the local threshold technique. Figure 4 shows comparisons among the 


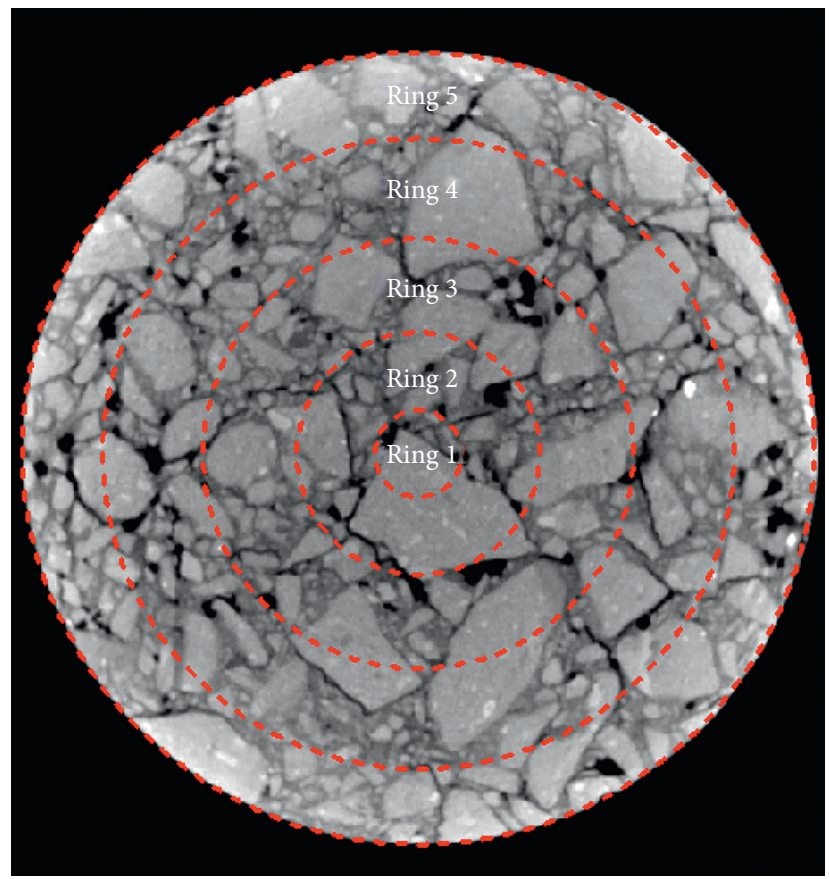

Figure 2: Segmentation of CT picture.

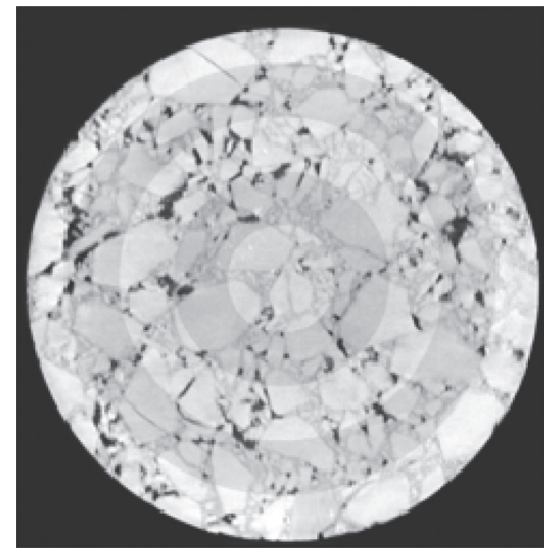

(a)

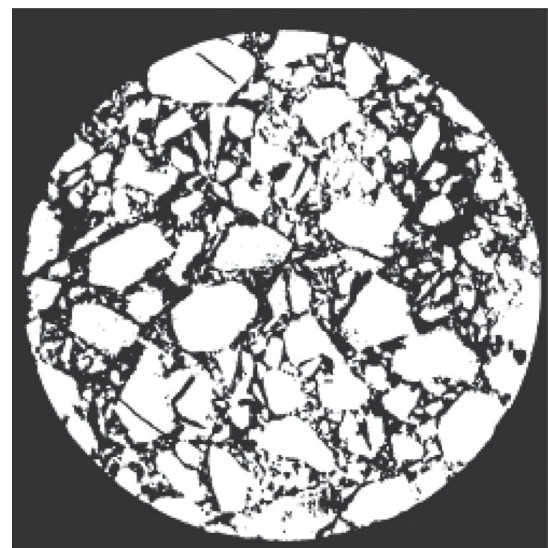

(b)

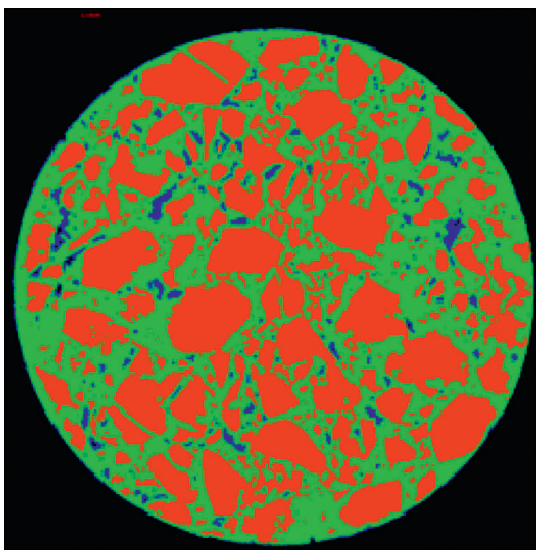

(c)

FIGURE 3: Segmentation image processed by 5-ring blocking [18]. (a) Segmentation with 5 rings (b) After segmentation with 5 rings. (c) After processed with segmentation and Otsu's method.

original CT picture processed by Bernsen's method, conventional Otsu's method, and ring segmentation using Otsu's method, respectively.

The variation in gray intensity of the CT image depends on the density of each material in the composite. Brighter regions correspond to denser objects, such as aggregates, and dark regions correspond to lower density objects, for instance, air voids. Figure 4(b) shows that Bernsen's method is hard to distinguish the fine aggregate and mastic inside the specimen. The conventional Otsu's method shown in Figure 4(c) can be used to capture fine aggregate structures. However, it cannot distinguish the denser structure of the fine aggregate and mastic. Therefore, it can be seen that the ring segmentation combining Otsu's method is the most effective, compared with other two methods to process the CT picture.

\section{Air Void of Asphalt Mixtures Analysis}

5.1. Air Void Distribution. The Image-Pro ${ }^{\circledR}$ Plus software and MATLAB software are used to visualize the air void structure of the asphalt mixture samples. The air void structure includes the radii, areas, and air void content. The percent air voids for an image $\left(\% \mathrm{AV}_{j}\right)$ and the total percent air voids of the sample $(\% \mathrm{AV})$ are computed as follows: 


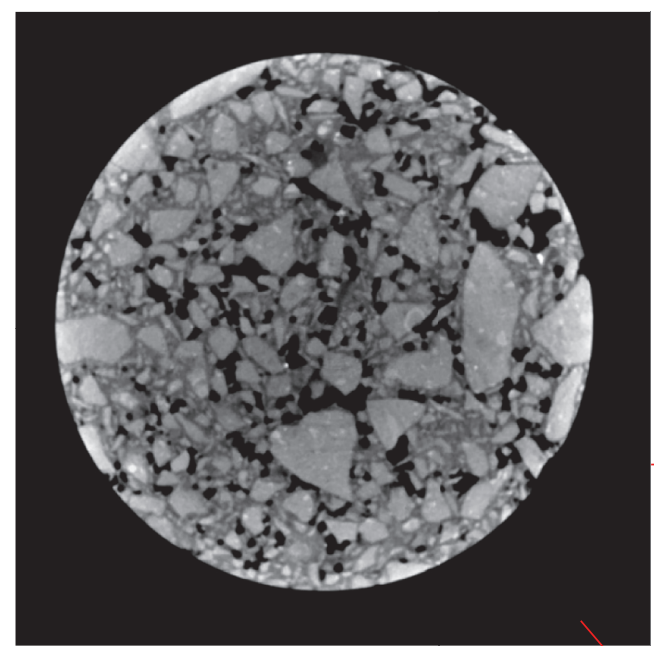

(a)

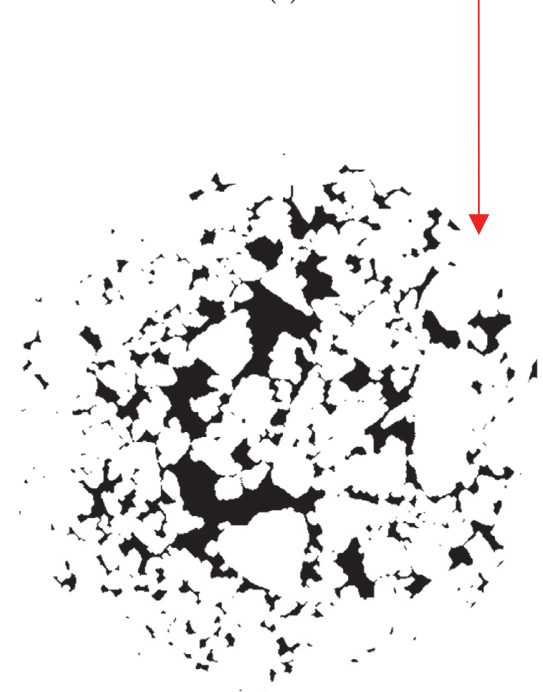

(c)

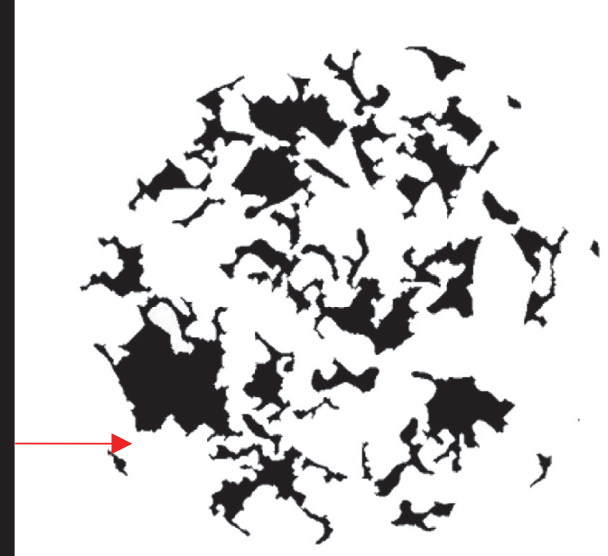

(b)

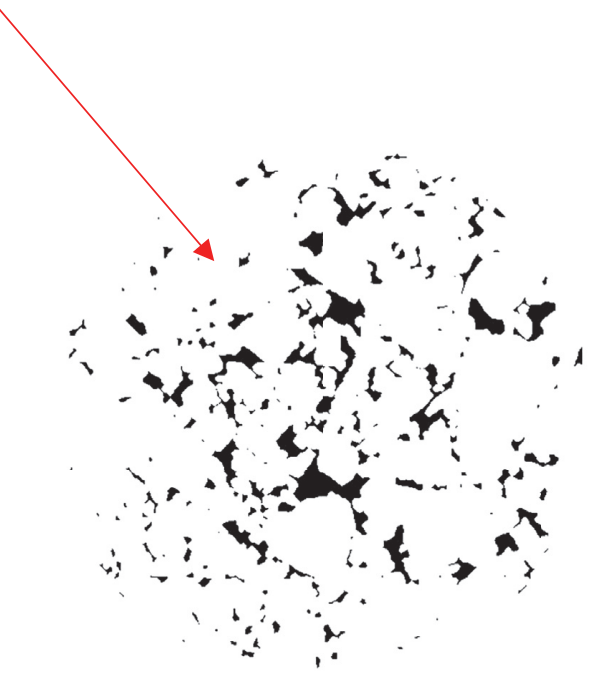

(d)

Figure 4: Comparisons among Bernsen, conventional Otsu, and ring blocking using Otsu's method. (a) Original CT picture. (b) Processed using Bernsen method. (c) Processed using conventional Otsu's method. (d) Processed using ring blocking using Otsu's method.

$$
\begin{aligned}
\mathrm{AAV}_{j} & =\frac{A_{v j}}{A_{j}}, \\
\% \mathrm{AV} & =\frac{\sum_{j=1}^{N} \% \mathrm{AV}_{j}}{N},
\end{aligned}
$$

where $A_{v j}$ is the area of air voids in image $j, A_{j}$ is the crosssectional area of image $j$, and $N$ is the total number of images. The air void radii in image $j$, also called air void size in this study, are computed as follows:

$$
\bar{r}_{j}=\sqrt{\frac{A_{v j}}{\pi M_{j}}},
$$

where $M_{j}$ is the number of air voids in each image. Several threshold values are used as input to the macro until the total percent air voids of the sample (equation (12)) matches the laboratory measurements.

Based on the aforementioned information, the air void content and air void size in terms of air void radius and area can be calculated. Figure 5 shows that the air void distributes along with the height of the specimen based on the CT picture. Each CT picture's air voids content can be calculated according to the modified Otsu's method. Figure 6 shows that the air void size plotted against the void number in SUP13, AC13, SMA13, and PA13 specimens. The air void size is represented by the air void radius which can be obtained from the air void area. The air void radius is used to evaluate the magnitude of air voids. The air void sizes of SUP13 and AC13 mainly are distributed from 0.15 to $0.2 \mathrm{~mm}$ in radius, following by 0.1 to $0.15 \mathrm{~mm}$ and 0.2 to $0.25 \mathrm{~mm}$. In terms of air void size greater than $0.3 \mathrm{~mm}$, the number is 9 and 2 for SUP13 and AC13, respectively. For PA13 specimen, the air void sizes mainly are distributed between 0.4 


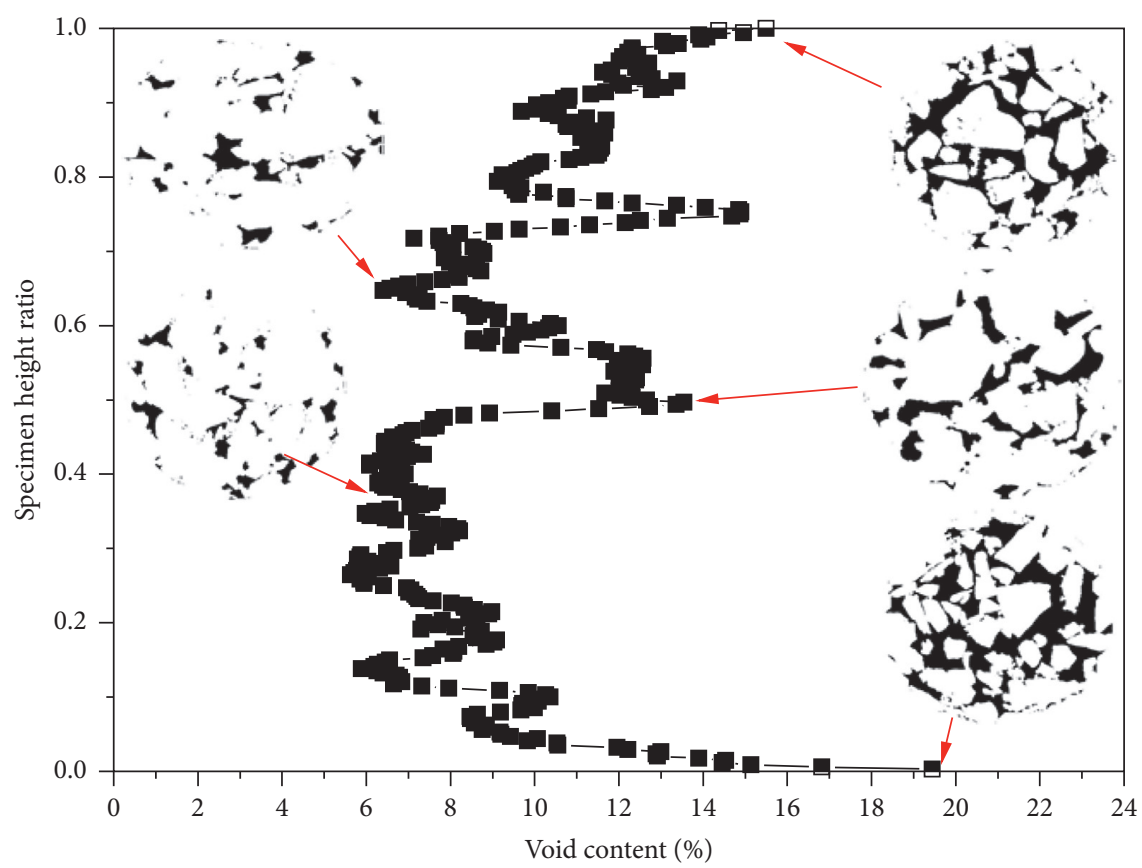

FIgURe 5: Air void distribution along with the height of specimen.

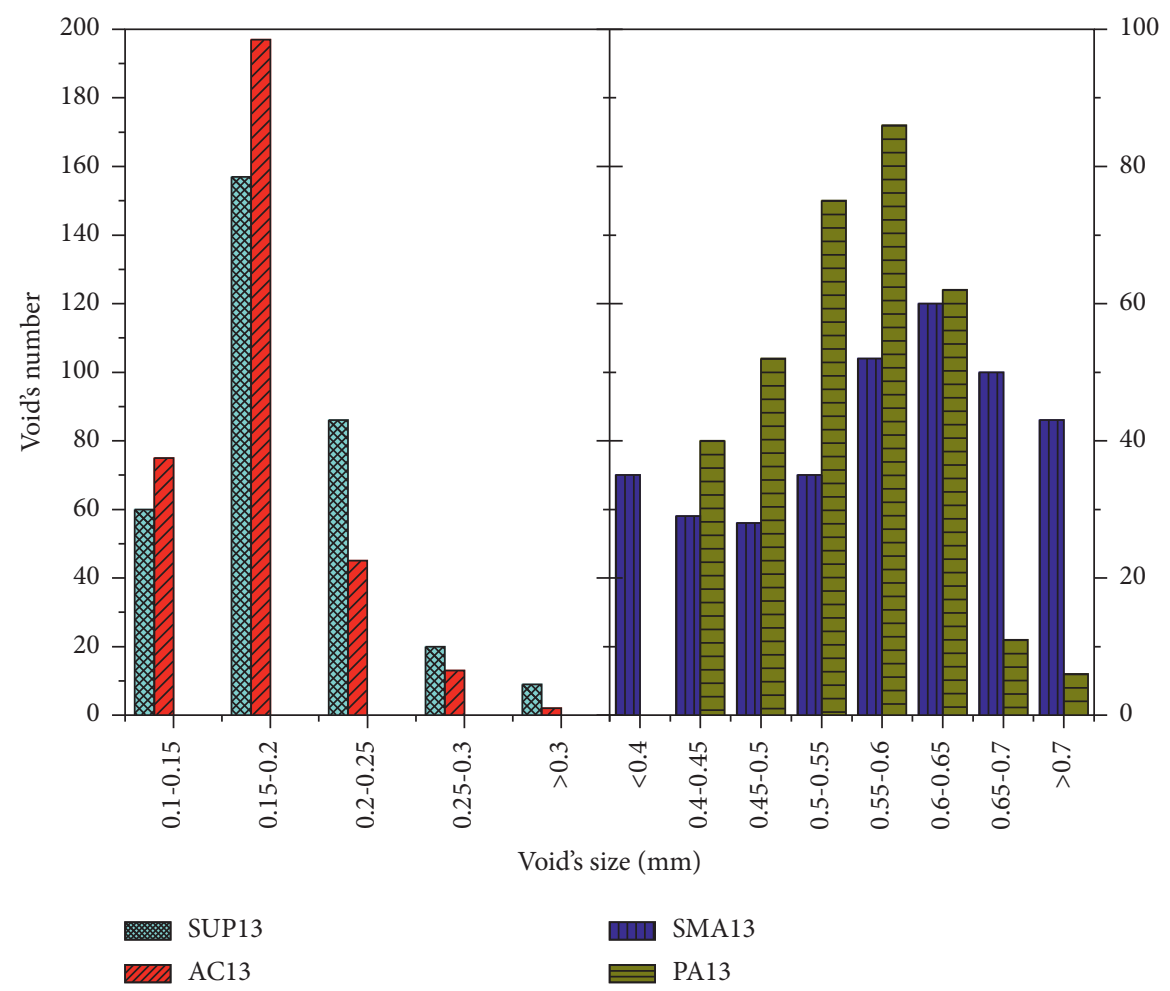

FIGURE 6: Air void size plotted against void number in SUP13, AC13, SMA13, and PA13 specimen.

and $0.65 \mathrm{~mm}$, especially from 0.5 to $0.65 \mathrm{~mm}$. For SMA13 specimen, the air void sizes have uniform distribution mainly ranging from 0.4 to $0.7 \mathrm{~mm}$.

Figures 7-10 depict air void size distributions along with the AC13, SUP13, PA13, and SMA13 specimens' height ratio. The height ratio along the $y$-axis is defined as the ratio of the vertical distance of a slice from the bottom of the specimen to the total height of the specimen. The air void radius, air void area, and air void content are plotted according to the analysis of processed CT pictures and air 


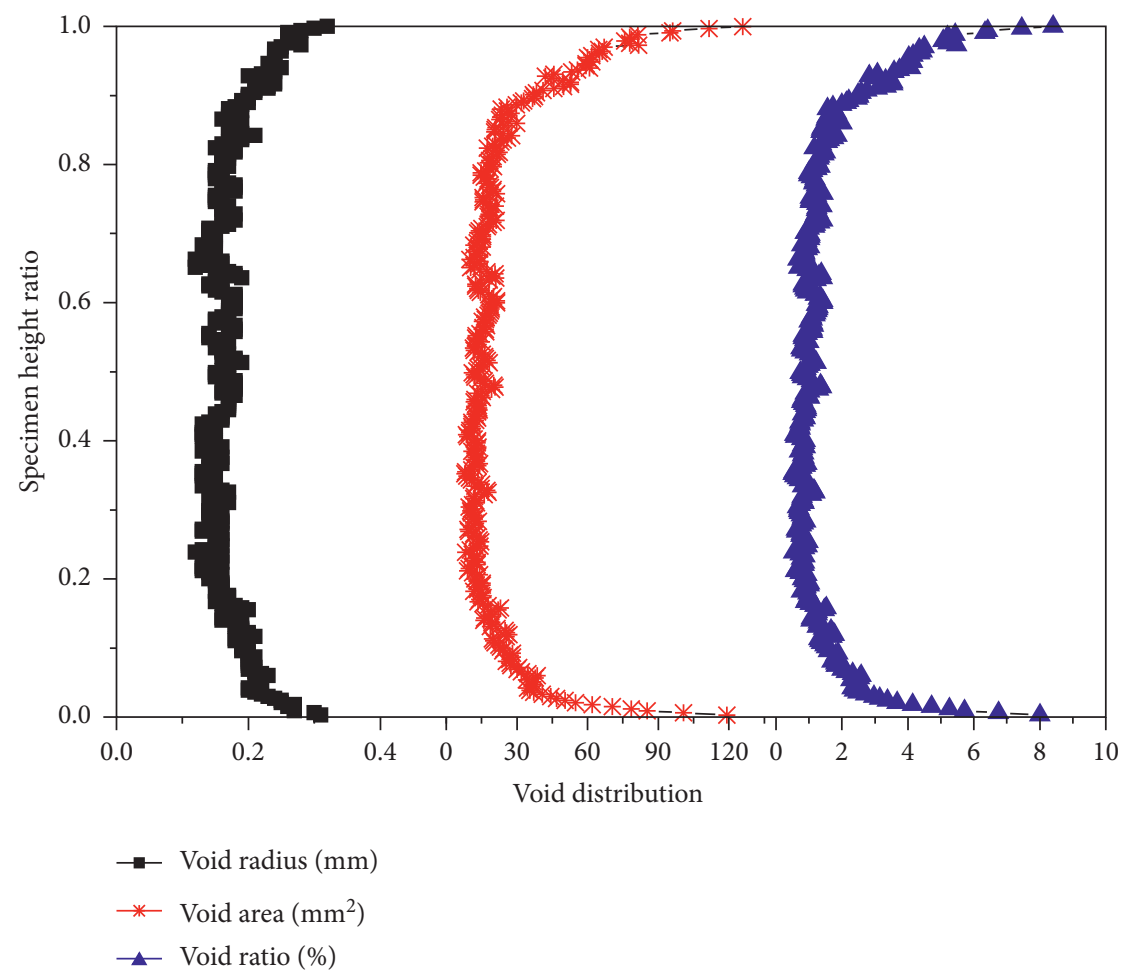

FIgUre 7: Air size distributions along with the AC13 specimen height ratio.

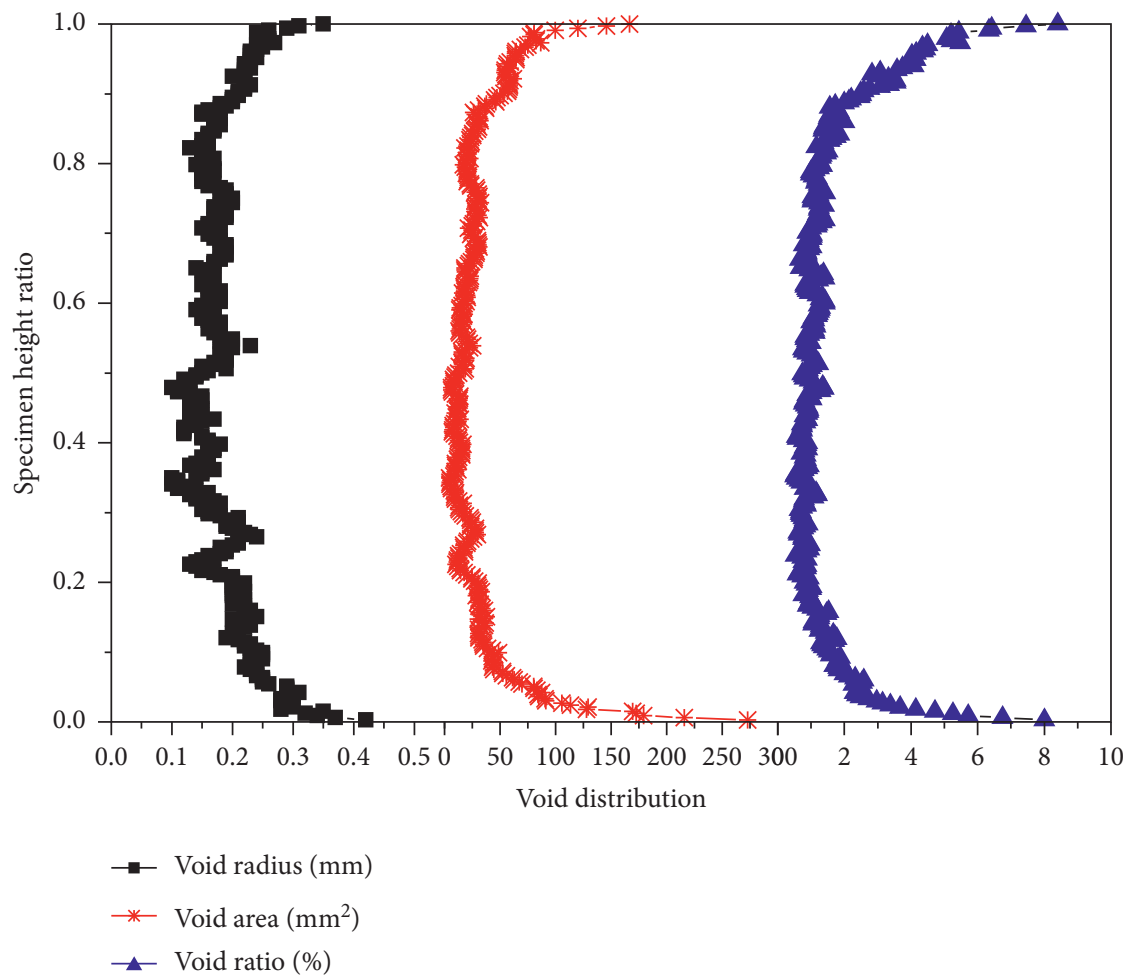

FIGURE 8: Air size distributions along with the SUP13 specimen height ratio.

void's distribution algorithm. For SUP13 and AC13 samples, the relationship between void content and depth is bathtub- shaped like. The porosity at the top and bottom of the sample is higher, and the porosity in the middle is lower and more 


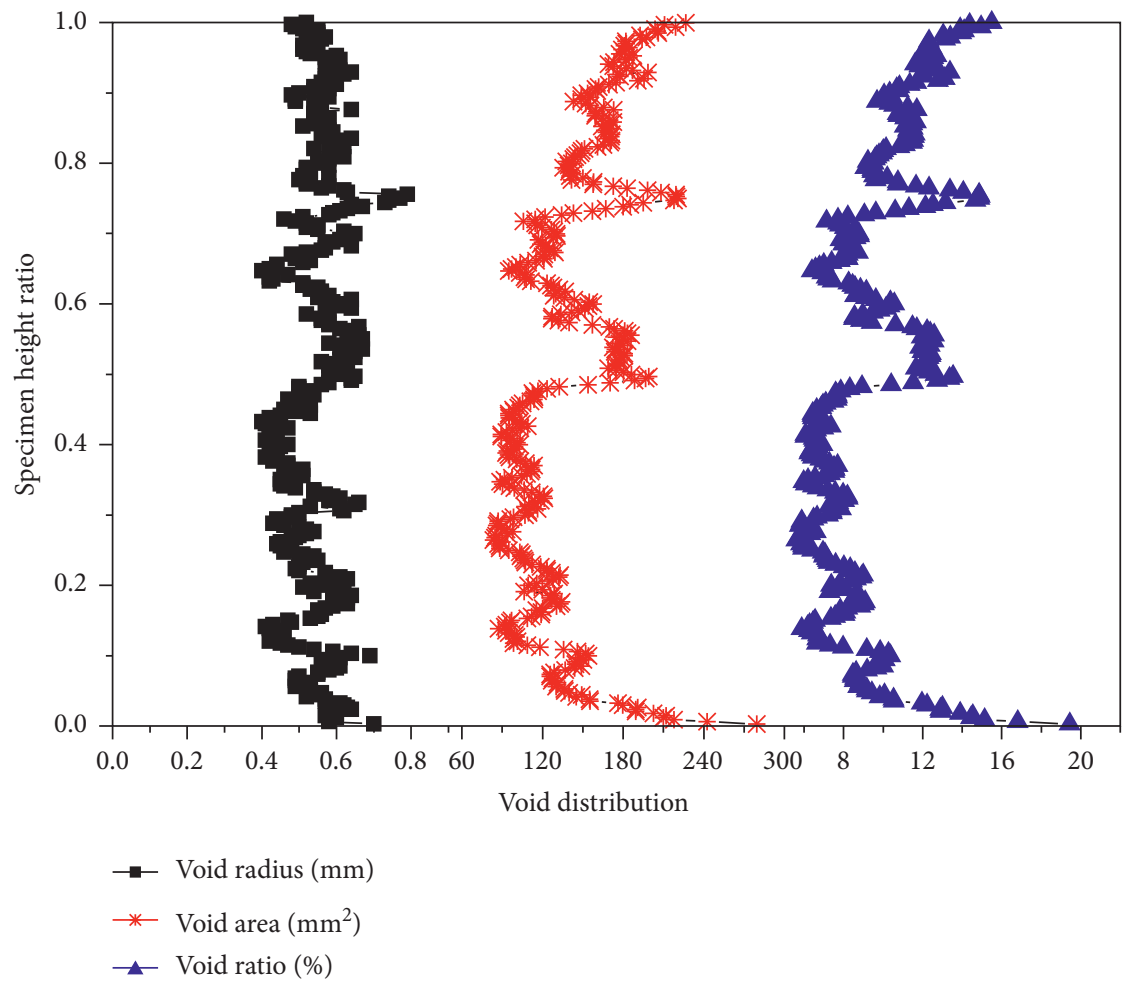

FIgURE 9: Air size distributions along with the PA13 specimen height ratio.

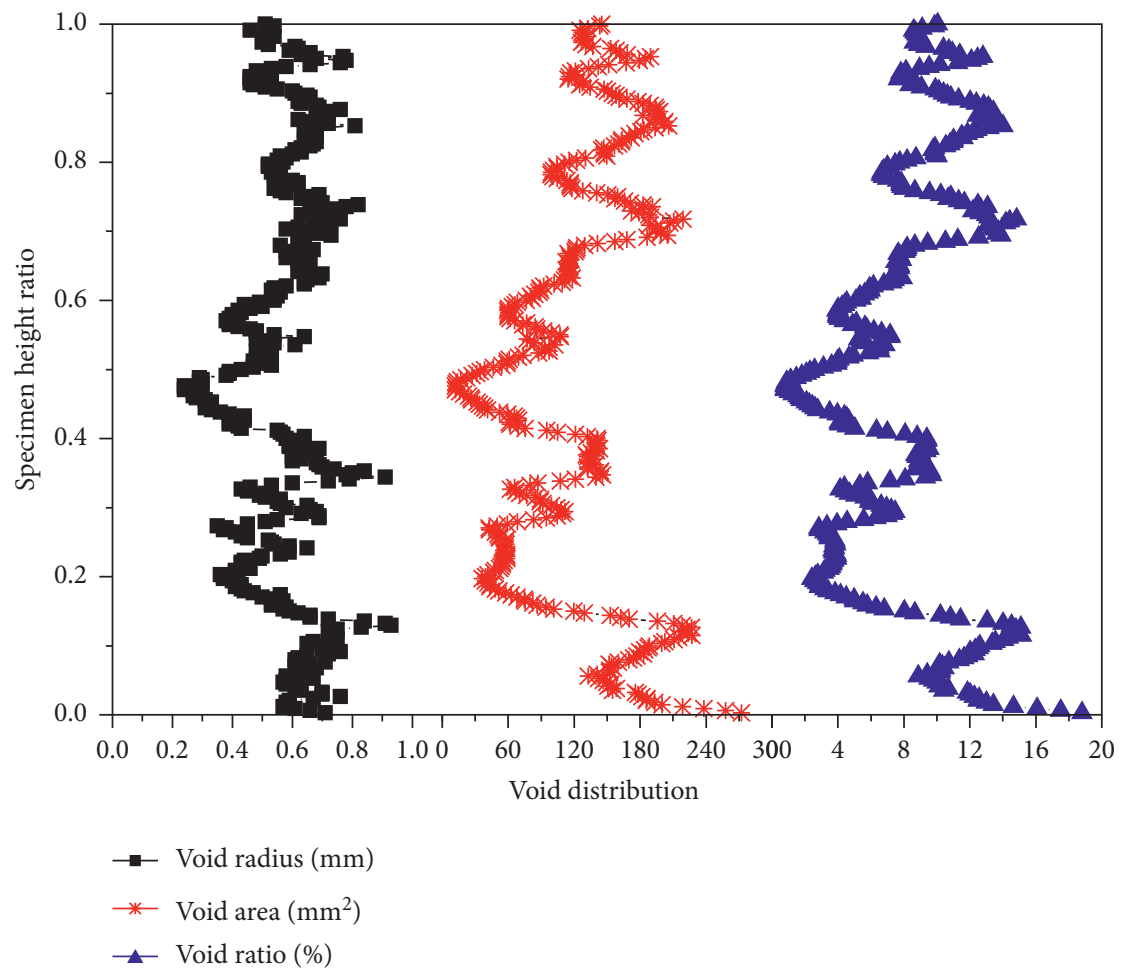

Figure 10: Air size distributions along with the SMA13 specimen height ratio.

uniform. The results for the SMA13 and PA13 samples show different trends, but in general, the air void content is higher at the top of the sample and lower in the rest of the sample depth. The results are comparable to the field cores, that is, the air void content is higher at the top of the sample and lower in the rest of the sample depth [20]. An internal trend 

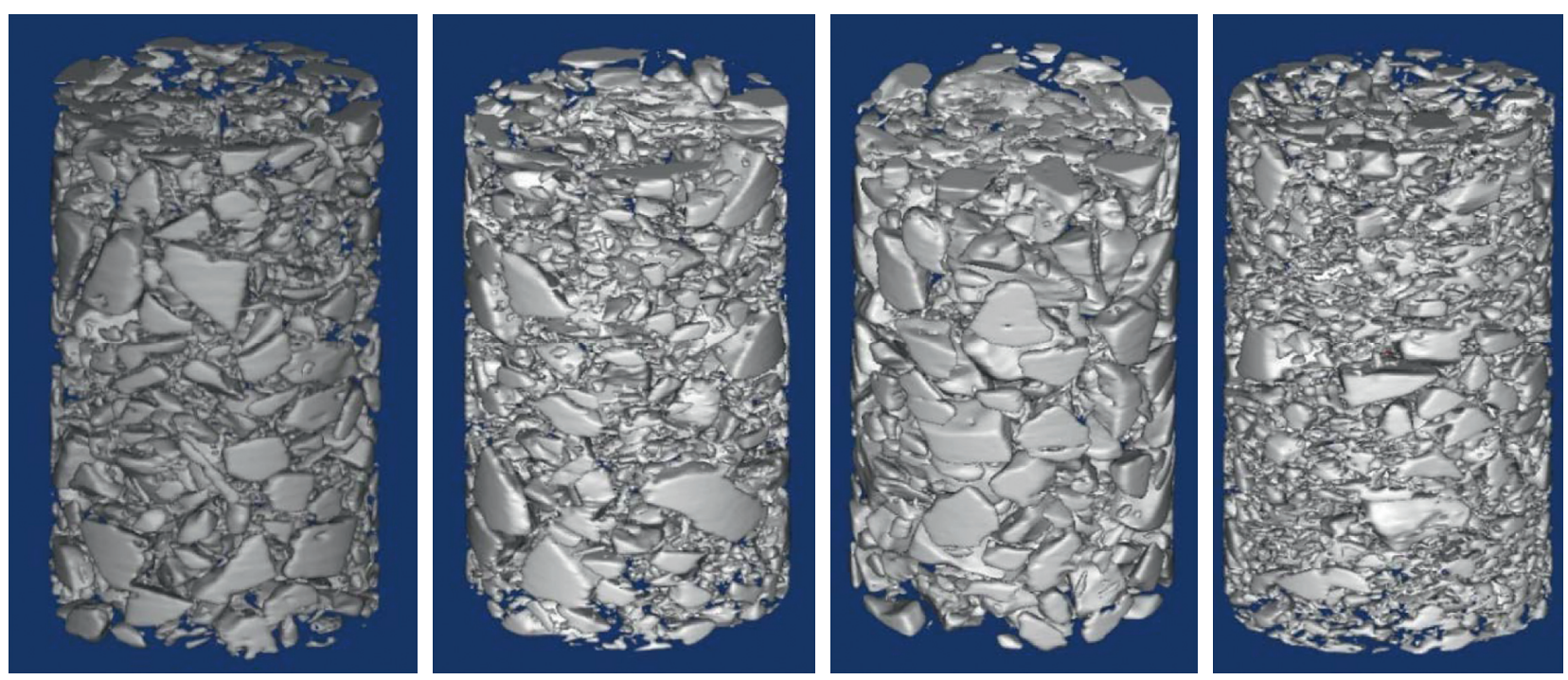

Figure 11: Reconstructed virtual specimens (PA13, AC13, SMA13, and SUP13, from left to right).

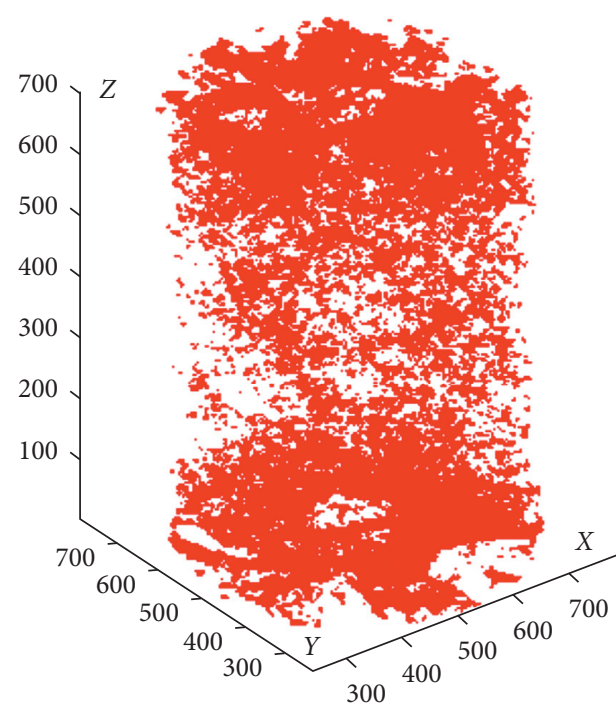

(a)

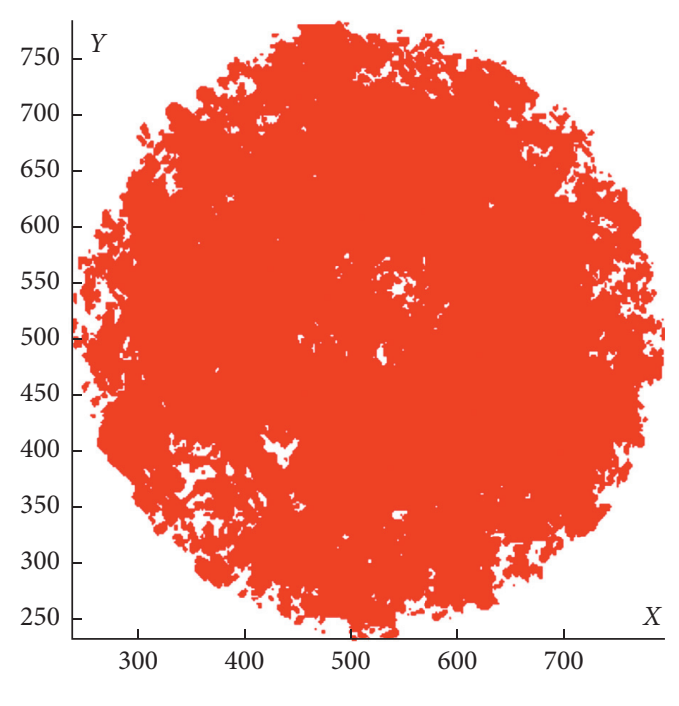

(b)

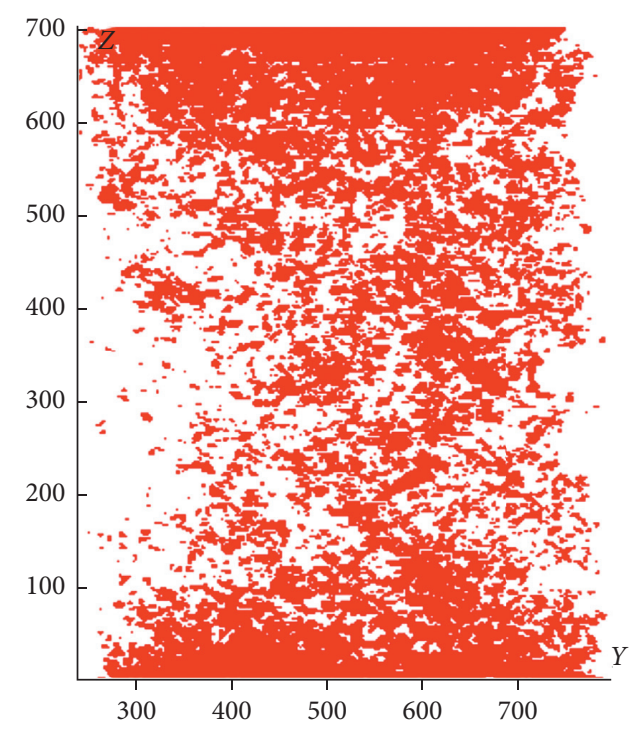

(c)

Figure 12: Air void distribution of AC13 specimen. (a) Three dimensions. (b) Projection in transverse section. (c) Projection in vertical section. 


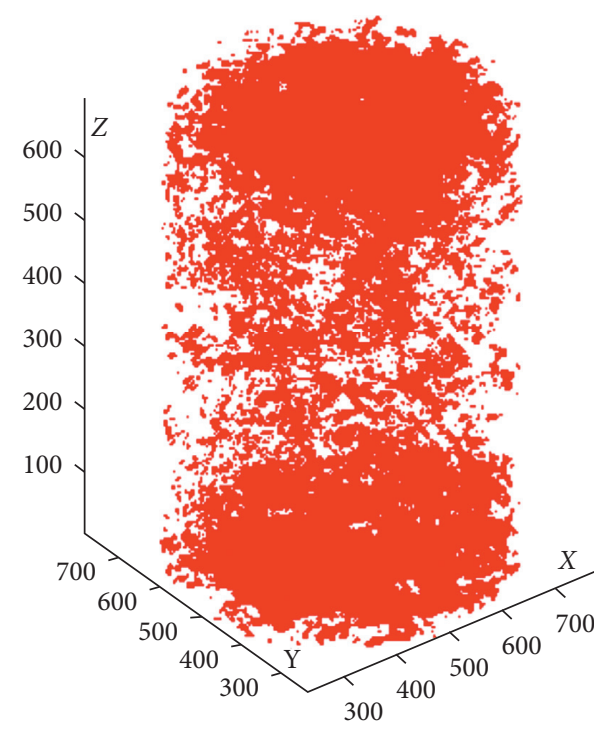

(a)

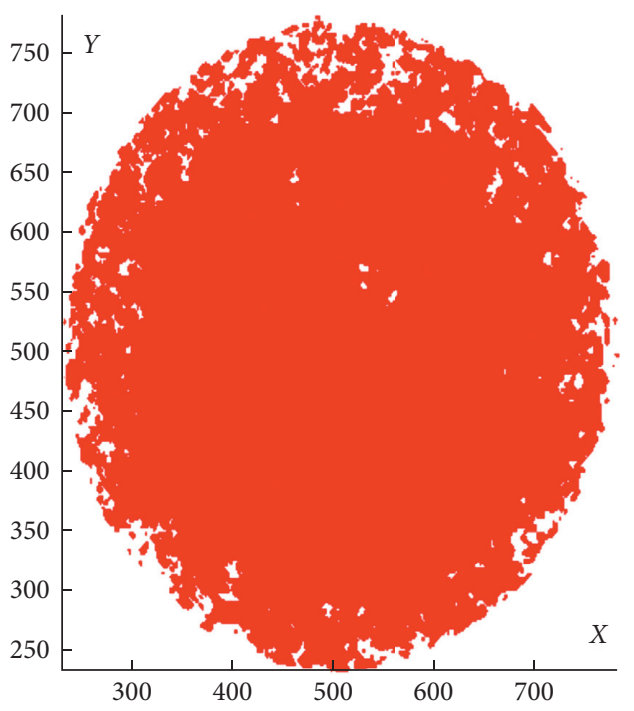

(b)

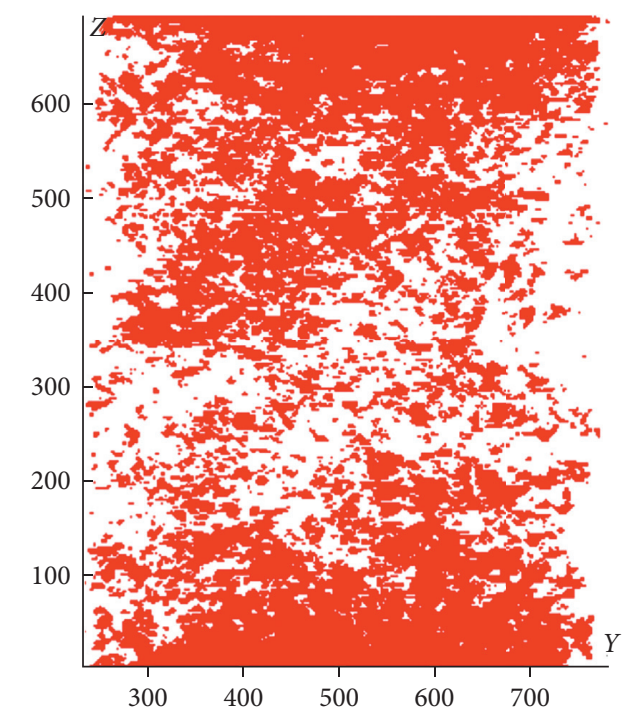

(c)

FIgUre 13: Air void distribution of SUP13 specimen. (a) Three dimensions. (b) Projection in transverse section. (c) Projection in vertical section.

in field sample air voids is roughly two times higher near the surface of the asphalt course than on the middle and bottom of the layer $[21,22]$. Figures $7-10$ indicate that the air void content is depend on the air void areas which relate to the air void size (that is, air void radius).

The graphs in Figures 7 and 8 are distinctively different than those in Figures 9 and 10. The reason for this is that the used large stones and SBS-modified binder in Figure 9 and high-viscosity binder in Figure 10. Both of these produce a more uniform distribution of air voids vertically, even though there is more variability in the air void content than is the case with Figures 7 and 8.

5.2. Air Void Distribution Reconstruction. In order to construct the three-dimension distribution of air voids, the commercially available software, MATLAB program, is used to reconstruct the processed CT pictures. Remove the particles with the particle size less than $1.18 \mathrm{~mm}$, and then reconstruct the four grading specimen model, as shown in Figure 11. The three-dimension air voids microstructure of asphalt mixtures are shown in Figures 12-15 for AC13, SUP13, PA13, and SMA13, respectively. The two-dimension CT images processed by ring blocking and Otsu's method are collected and converted into three-dimension image of the original sample. The images are thresholded to identify mixture constituents. Thresholding is the technique applied to characterize the components of the mixture. It converts the representative gray scale of a component into a value. This value is the only value associated with an element, and so it can be identified in the mixture. The gray value is assigned to air voids. The reconstruction of air voids of 


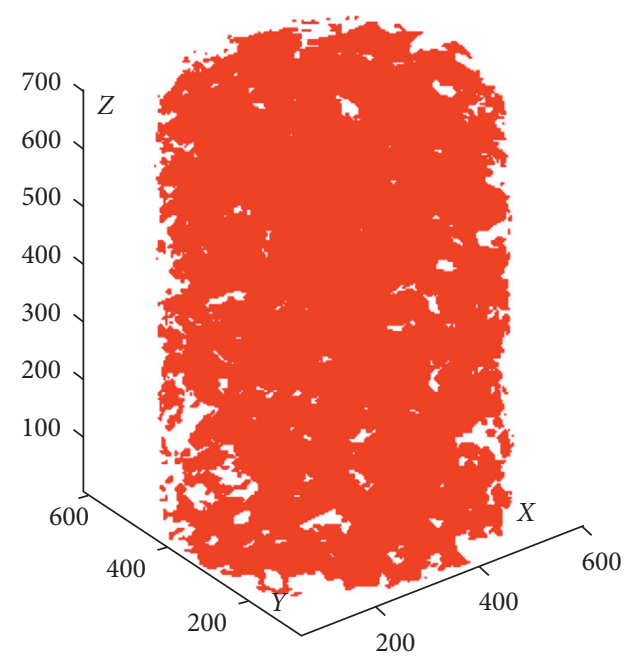

(a)

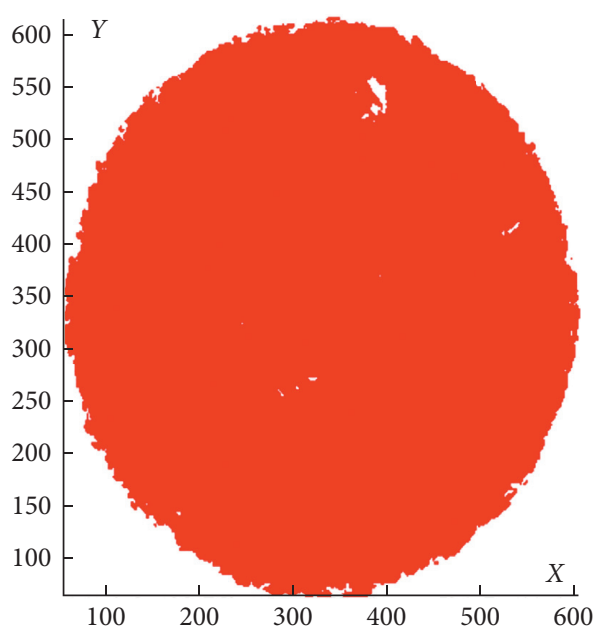

(b)

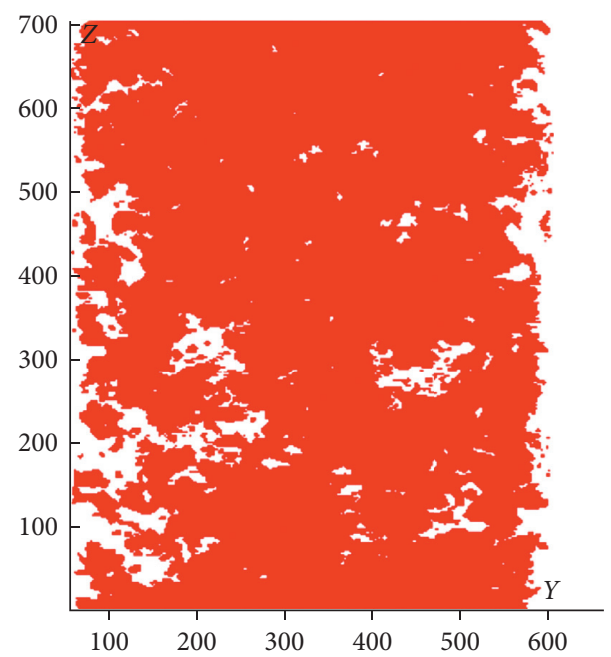

(c)

Figure 14: Air void distribution of PA13 specimen. (a) Three dimensions. (b) Projection in transverse section. (c) Projection in vertical section.

asphalt mixtures can be simply carried out as in the following steps. Firstly, the horizontal slices of $1.0 \mathrm{~mm}$ thickness with an overlap of $0.2 \mathrm{~mm}$ were captured. Secondly, these slices were stacked together in the computer to form the actual three-dimension porous microstructure. Thirdly, the three-dimension structure of air voids is rotated to project in transverse section and vertical section.

It appears in Figures 12 and 13 that the distributions of the air void content of SUP13 and AC13 with respect to depth coincide with those in Figures 7 and 8; a higher air void content was observed at the sample top and bottom, while lower and more uniform air void content were observed in the middle section. Figures 14 and 15 show different trends compared with SUP13 and AC13, and in general, the air void content is higher at the top of the sample and lower in the rest of the sample depth. And the air void's distribution seen from Figures 14 and 15 are in line with Figures 9 and 10, respectively. It indicates that the CT pictures processed by the ring blocking segmentation and Otsu's method are feasible and rational to capture the air voids size and content of asphalt mixtures.

\section{Conclusions and Discussion}

The X-ray CT was used to scan the specimens of AC13, SUP13, PA13, and SMA13. The CT pictures were processed by ring blocking segmentation and calculated by Otsu's method. Based on preprocesses, segmentation, and identification, the air voids of asphalt mixtures were calculated and reconstructed with Image-Pro ${ }^{\circledR}$ Plus software and MATLAB program. The key findings are summarized as follows: 


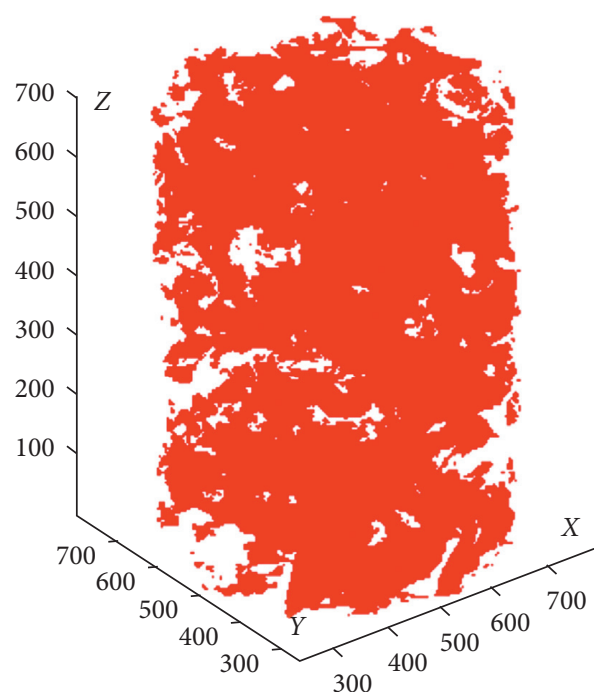

(a)

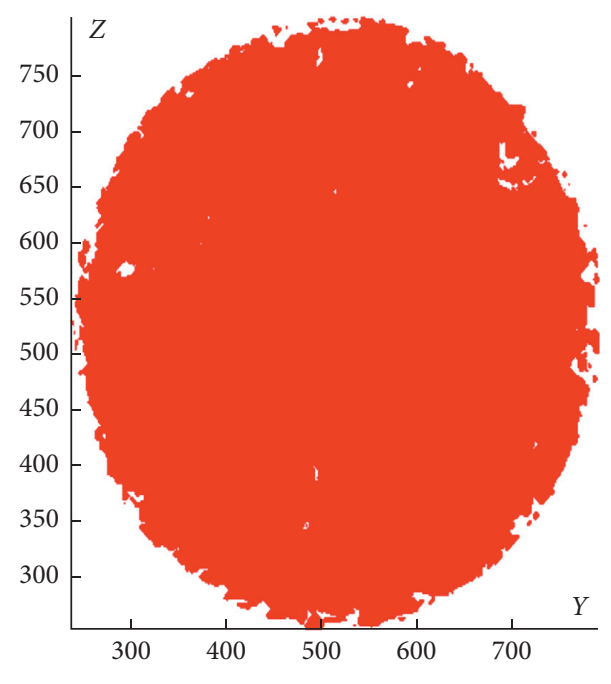

(b)

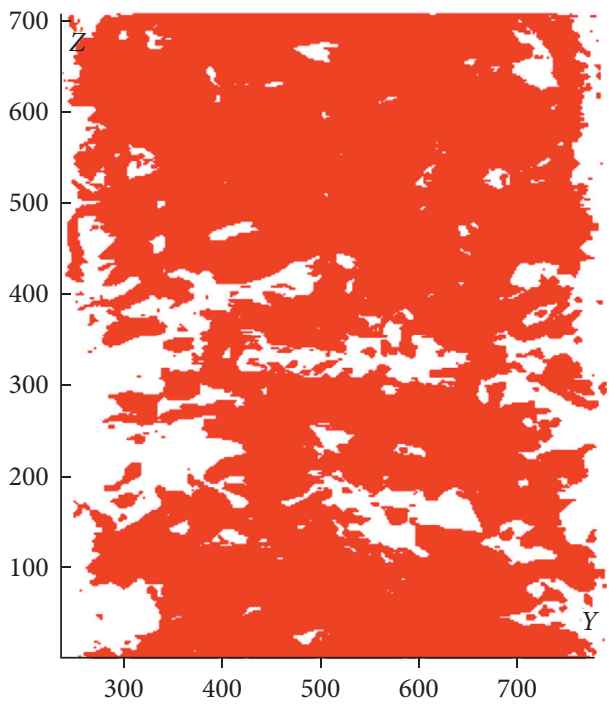

(c)

Figure 15: Air void distribution of SMA13 specimen. (a) Three dimensions. (b) Projection in transverse section. (c) Projection in vertical section.

(1) The air voids of AC13, SUP13, PA13, and SMA13 specimens can be distinct to capture using the ring blocking segmentation combining Otsu's method to process the CT pictures.

(2) According to the analysis of method processed, it is believed that the ring blocking segmentation combining Otsu's method is feasible and rational to identify the air voids of asphalt mixtures in comparison with Bernsen's method and the conventional Otsu's method.

(3) The air void sizes of SUP13 and AC13 are mainly distributed between 0.15 to $0.2 \mathrm{~mm}$, while it is mainly distributed between 0.4 and $0.65 \mathrm{~mm}$ for PA13. For SMA13 specimen, the air voids sizes have uniform distribution mainly ranging from 0.4 to $0.7 \mathrm{~mm}$.
(4) Image analysis reveals that air void's distribution is not uniform through the specimens, namely, higher air voids concentrations were found at the specimen's top and bottom and lower air voids in between.

(5) It is a significant progress of asphalt mixtures' research to conduct three-dimensional reconstruction of the air voids. The air voids of SUP13, AC13, SMA13, and PA13 were reconstructed and displayed. The three-dimensional air voids distribution of AC13, SUP13, PA13, and SMA13 are in accordance with the analysis of air void size distribution along with the height ratio of specimen.

(6) The used large stones and SBS-modified binder in SMA13 and high-viscosity binder in PA13 produce a more uniform distribution of air voids vertically, 
even though there is more variability in the air void content than is the case with AC13 and SUP13.

\section{Data Availability}

The Fish code data and Excel data of experiment used to support the findings of this study were supplied by the National Natural Science Foundation of China and China Postdoctoral Science Foundation under license and so cannot be made freely available. Requests for access to these data should be made to Jiantong Zhang, tongtong01@ 126.com.

\section{Conflicts of Interest}

The authors declare that they have no conflicts of interest.

\section{Acknowledgments}

The authors gratefully acknowledge the financial assistance provided by the National Natural Science Foundation of China (No. 51078089) and China Postdoctoral Science Foundation (No. 2016M590717).

\section{References}

[1] C. L. Monismith, "Analytically based asphalt pavement design and rehabilitation," vol. 1354, pp. 5-26, Transportation Research Record, 1992.

[2] T. K. Pellinen, J. Song, and S. Xiao, "Characterization of hot mix asphalt with varying air voids content using triaxial shear strength test," in Proceedings of the 8th Conference on Asphalt Pavements for Southern Africa (CAPSA'04), Sun City, South Africa, September 2004.

[3] E. Masad, V. K. Jandhyala, N. Dasgupta, N. Somadevan, and N. Shashidhar, "Characterization of air void distribution in asphalt mixes using X-ray computed tomography," Journal of Materials in Civil Engineering, vol. 14, no. 2, pp. 122-129, 2002.

[4] F. Beainy, S. Commuri, and M. Zaman, "Quality assurance of hot mix asphalt pavements using the intelligent asphalt compaction analyzer," Journal of Construction Engineering and Management, vol. 138, no. 2, pp. 178-187, 2012.

[5] S. Caro, E. Masad, and M. Sánchez-Silva, "Stochastic micromechanical model of the deterioration of asphalt mixtures subject to moisture diffusion processes," International Journal for Numerical and Analytical Methods in Geomechanics, vol. 35, no. 10, pp. 1079-1097, 2011.

[6] E. Little, Compaction Effects on Uniformity, Moisture Diffusion, and Mechanical Properties of Asphalt pavements, Thesis (PhD), Texas A\&M University, Fort Worth, TX, USA, 2008.

[7] Q. Xu, K. C. George, L. G. Victor, and D. H. Robert, "Influences of intelligent compaction uniformity on pavement performances of hot mix asphalt," Construction and Building Materials, vol. 30, pp. 746-752, 2011.

[8] D. Caro and C. Silvia, "Effects of air voids variability on the thermo-mechanical response of asphalt mixtures," International Journal of Pavement Engineering, vol. 15, no. 2, pp. 110-121, 2014.

[9] L. F. Walubita, B. Jamison, A. E. Alvarez, X. Hu, and C. Mushota, "Air void characterisation of HMA gyratory laboratory-moulded samples and field cores using X-ray computed tomography (X-ray CT)," Journal of The South
African Institution of Civil Engineering, vol. 54, no. 1, pp. 22-30, 2012.

[10] L. F. Walubita and S. Scullion, "Perpetual pavements in texas: the fort worth sh 114 perpetual pavement in wise county," Technical Report No. FHWA/TX-05/0-4822-2), Texas A\&M University, Fort Worth, TX, USA, 2007.

[11] L. F. Walubita and S. Scullion, Texas Perpetual Pavements: Experience Overview and the Way Forward, FHWA/TX-10/04822-3, TTI, College Station, TX, USA, 2010.

[12] C. Denison, W. D. Carlson, and R. A. Ketcham, "Three-dimensional quantitative textural analysis of metamorphic rocks using high-resolution computed X-ray tomography: Part I. Methods and techniques," Journal of Metamorphic Geology, vol. 15, no. 1, pp. 29-44, 1997.

[13] E. Masad, B. Muhunthan, N. Shashidhar, and T. Harman, "Internal structure characterization of asphalt concrete using image analysis," Journal of Computing in Civil Engineering, vol. 13, no. 2, pp. 88-95, 1999.

[14] L. F. Walubita, T. Scullion, J. Leidy, and W. Liu, "Non-destructive testing technologies application of the ground penetrating radar (GPR) to perpetual pavements," Road Materials and Pavement Design, vol. 10, no. 2, pp. 259-286, 2009.

[15] Ministry of Transport, Standard Test Methods of Bitumen and Bituminous Mixtures for Highway Engineering. JTG E20-2011, Ministry of Transport, Beijing, China, 2011.

[16] N. Otsu, "A threshold selection method from gray-level histograms," IEEE Transactions on Systems, Man, and Cybernetics, vol. 9, no. 1, pp. 62-66, 1979.

[17] X.-ning Zhang, DuanYue-hua, and Li Zhi, "Classi_cation of asphalt mixture materials based on X-ray computed tomography," Journal of South China University of Technology (Nature Science Edition), vol. 39, no. 03, pp. 120-123, 2011, in Chinese.

[18] Li Zhi and J. Liu, "Segmentation of asphalt mixtures using Xray computed tomography images based on ring block and OTSU method," Journal of Wuhan University of Technology, vol. 33, no. 6, pp. 50-53, 2011.

[19] P. K. Sahoo, A. K. C. Wong, and Y. C. Chen, "A survey of thresholding techniques," Computer Graphics,Vision and Image Processing, vol. 41, no. 3, pp. 233-260, 1988.

[20] L. Tashman, E. Masad, J. D’Angelo, J. Bukowski, and T. Harman, "X-ray tomography to characterize air void distribution in superpave gyratory compacted specimens," International Journal of Pavement Engineering, vol. 3, no. 1, pp. 19-28, 2002.

[21] L. Tashman, M. Eyad, B. Peterson, and H. Saleh, "Internal structure analysis of asphalt mixes to improve the simulation of superpave gyratory compaction to field conditions," Asphalt Paving Technology, vol. 70, pp. 605-645, 2001.

[22] E. Masad, K. Emad, and C. Arif, Application of Imaging Technology to Improve the Laboratory and Field Compaction of HMA, Texas Transportation Institute (TTI), The Texas A\&M University System, College Station, TX, USA, 2009. 